\title{
CINEMA AFRICANO EM FOCO: ENTREVISTA COM O CINEASTA
}

\section{SOL DE CARVALHO}

\section{Doutora Maria Geralda de Miranda UNISUAM/UERJ}

http://dx.doi.org/10.17074/2176-381X.2015v12n1p21

Biografia resumida do entrevistado:

João Luís Sol de Carvalho nasceu em 1953, em Moçambique. De 1972 a 1974 estudou cinema em Portugal. Logo após o fim do regime salazarista regressou ao seu país natal para se juntar à Frente de Libertação de Moçambique, FRELIMO. Neste período participou também no projeto Kuxa Kanema, que consistia em filmar a imagem do povo e devolvê-la ao povo. Foi diretor da Rádio Moçambique e da revista Tempo. Em 1986 abraça definitivamente a carreira cinematográfica e já realizou, de lá para cá, mais de 20 filmes, entre eles $O$ Jardim do Outro Homem, A Janela, O Búzio, As Teias da Aranha. As suas obras são conhecidas pelo cunho social e pedagógico.

MGM - A partir das lutas pela independência, percebemos uma reviravolta no cinema africano, principalmente com diretores africanos (o mais conhecido deles Ousmane Sembene) que produziram filmes nos quais a África fala de si para o mundo em contraponto às leituras tradicionais hollywoodianas e eurocêntricas. Como você analisa este período e sua contribuição para o cinema moçambicano?

SC- Sembene, Cissé, Gerima e os realizadores do Magreb foram fundamentais nessa viragem que correspondia também a uma "voragem" de afirmação de identidade. Ainda bem que assim foi. As obras são poucas. Algumas toscas, mas cheias de algo quase imperceptível que era essa vontade de mergulhar na realidade africana. As marcas continuam até hoje. No imediato pós-independência, a nação moçambicana estava em ruptura com o imperialismo. Procurava uma identidade nacional e marxista, pelo que não é de estranhar que se procurasse ver esse cinema que acabava de despontar no continente. É curioso perceber hoje em dia que esse cinema desapareceu das nossas salas e que Hollywood voltou. Mas não desapareceu nas nossas consciências nem da nossa maneira de fazer cinema... Creio que a marca (talvez a mais importante de todas seja o absoluto privilégio às temáticas sociais) ainda se mantem...

MGM - O que foi o projeto KUXA KANEMA, seus propósitos iniciais, e sua importância para o desenvolvimento do cinema Moçambicano?

SC - Não havia uma escola de cinema. Não havia televisão no início da década de 1980. O cinema estava institucionalmente ligado ao Ministério da Informação e os 
documentários de atualidades, em película, ainda estavam presentes na memória. $O$ poder político precisava de um instrumento que pudesse difundir largamente os principais acontecimentos e a mensagem do regime. A solução foi a de criar um departamento que produzisse 11 minutos de notícias semanais, totalmente produzidos em Moçambique, enquanto o restante do Instituto de Cinema se dedicaria à produção de documentários e ficções. Assim foi criado o KUXA KANEMA (que quer dizer "imagem em movimento" em línguas nacionais), que durou cerca de 8 anos... Creio que o mais importante foi mesmo a capacidade de se fazer 11 minutos semanais "in house", incluindo laboratório. E, depois, conseguir 12 cópias em 35mm e 3 em 16mm, sendo as primeiras mostradas nos cinemas e as segundas na vilas e aldeias. $O$ objetivo de formação não foi tão conseguido quanto se desejava. Mas, criou-se espaço para que os cineastas se pudessem dedicar a outros documentários e ficções, que corresponderam ao momento áureo do cinema moçambicano: Madrugada Suburbana, Não mataram o sonho de Patrício, Um dia nas Aldeias Comunais, Pamberi Zimbabwe, Canta Meu Irmão, Ensina-me A Cantar, e as ficções O Vento Sopra do Norte e Tempo dos Leopardos. São o resultado dessa nossa organização. Daquela que era a instituição única que produzia, distribuía e exibia o cinema.

MGM - Fale um pouco sobre a história do cinema moçambicano, e, principalmente, sobre esta última fase em que foram produzidos filmes como 0 grande Bazar, $O$ último Voo do Flamingo, Virgem Margarida e 0 Jardim do Outro Homem.

SC- Aqui já estamos numa época em que o INC se havia desestruturado (também em resultado da assunção da economia de mercado por Moçambique), e em que os realizadores/produtores tinham abandonado o mesmo, e criado as produtoras independentes. De qualquer das formas, O Jardim do Outro Homem foi realizado em 2005, juntamente com o Grande Bazar. E tinham-se passado 20 anos desde a última produção nacional de ficção. São quase todos os filmes financiados internacionalmente, em que os realizadores moçambicanos procuram os fundos internacionais ligados à África para se subsidiarem.

MGM - Sua cinematografia aborda principalmente questões sociais, como a AIDS, a VIOLÊNCIA DOMÉSTICA, as periferias da cidade... e de forma questionadora. Qual tem sido o impacto do tratamento desta temática no público espectador? 
SC- Meus filmes estão quase sempre associados a projeções nas comunidades. $O$ Jardim esteve em festivais, ganhou prêmios, estreou em salas, mas percorreu o país num projeto chamado Cinema Arena. Foi aí que atingiu inúmeros espectadores. Foi aí que foi discutido. Pena que o poder político tenha tido medo de passá-lo nas escolas. Estivemos em negociação durante meses, mas perdi essa batalha. Passou depois em escolas, mas por iniciativa de ONG ou privadas, e não de uma forma que poderia ter contribuído realmente para uma mudança. O Teias da Aranha (minha segunda ficção) teve 400 exibições nas comunidades. Enviei pouco esse filme para o circuito internacional, embora ele tivesse propostas estéticas interessantes, do meu ponto de vista. Mas, percebi, finalmente, aqui, o que Godard me falava quando dizia que tinha um povo virgem em cinema e que, por isso, éramos mais ricos do que os países mais desenvolvidos... A problemática era eminentemente social (SIDA, emprego, gênero etc). Mas a história tinha sido construída sem qualquer imposição, com plena liberdade e identificação com o que estávamos a tratar. Já o Impunidades Criminosas foi um projeto que nasceu de um curta e se transformou num longa, em que eu pretendi alguma ruptura com o discurso, politicamente correto, tradicional da libertação feminina. Mas quero lembrar que o primeiro filme de amor do cinema moçambicano pós- independência também é meu. Foi filmado em película e chamase $A$ janela.

MGM - O cinema africano, desde Ousmane Sembene, passando por Flora Gomes, Licínio Azevedo e (você) Sol de Carvalho, tem abordado incansavelmente o feminino. Normalmente, a personagem central é a mulher simples da aldeia, ou da periferia, quase uma anti-heroína, se comparada às heroínas românticas. $\mathrm{E}$ isto acontece dentro de culturas predominantemente patriarcais. Em seu filme $O$ Jardim do outro homem as principais personagens são femininas e os homens normalmente representam o lado vilão da história. Gostaria de falar sobre isto?

SC- Sim, o tema geral é esse. Mas eu introduzo, quase sempre, alguma "nuance". Em $O$ Jardim é algo que passou despercebido à maioria da crítica internacional, mas que era frequentemente notado nas projeções com a população. Era a não existência de homens na família! O vilão era um homem, mas a força da batalha, que estava na família, em volta da heroína, era toda composta de mulheres (Sofia, a heroína; a irmã; a mãe; e, finalmente, a avó). Em contraponto quase irônico, eu coloquei propositadamente uma criança do sexo masculino e o jovem irmão que partilha o espaço dela. E, se reparam, trata-se do membro mais frágil, pois a criança 
está sempre doente e adensa o drama da heroína. Se me perguntar por que essa minha atração pelo personagem feminino, eu diria que pode haver algo de catarse da minha educação machista. Mas, também, porque encontrei sempre melhores personagens femininas. Mas, também, porque realmente eu admiro essa força, muitas vezes escondida, com que as mulheres enfrentam o mundo... Não é exclusivo mas, de repente, dei-me mais tarde conta de que tinha feito 5 filmes sobre a condição feminina em Moçambique.

MGM - Em sua opinião, existe uma estética cinematográfica africana? Se existe, o que ela incorpora da cultura milenar dos povos africanos? $\mathrm{E}$ já que vivemos em um mundo "globalizado", o que ela incorpora de outras influências como a americana, a europeia e a indiana, que sabemos ser marcante em Moçambique?

SC- No dia em que conseguirmos perceber porque certas correntes são mais aceitas em África do que outras, teremos encontrado uma mina e eu espero que haja garimpeiros capazes de a explorarem. Na década de 1970 e 1980, estudei largamente o cinema de Kung-Fu, de Bruce Lee, a partir de um acidente de um empregado da casa que se tinha deixado cair de uma árvore, imitando um ataque do herói. A Ros Gray, talvez a mais profunda investigadora do cinema moçambicano, citou no seu trabalho um artigo de 11 páginas que eu escrevi, numa revista sobre o cinema de Kung Fu em Moçambique. A minha tese era simples: a identificação decorria de que as armas do herói eram, por princípio, acessíveis ao espectador. As mãos, os punhos, o corpo são as armas usadas para combater o vilão (que, quase sempre, também é um opressor e rico). Não havia pistolas, ao contrário do cinema de cowboy. Então, a identificação era social e pessoal. E, por isso, mais forte. O mesmo se pode dizer sobre os temas das relações humanas (onde o cinema indiano e a telenovela ganham absoluta primazia). Há uma relação de proximidade e, ao mesmo tempo, de sonho. Ora, eu creio que os espectadores procuram isso no cinema. Já a proposta europeia da reflexão, dos heróis "distanciados" e racionais, não tem sucesso, até porque, à partida, estes são propositadamente complexos, racionais e distantes. Alguns são importantes e fundamentais até. Mas outros são apenas exercícios destinados a nichos fechados e aí se alojam e reproduzem... Depois, eu acho que os meios de produção decidem sobre a estética. Seria interessante ver que - talvez pelo fato do cinema ser de financiamento estatal na Europa - se criou certo estilo de fazer cinema. Isso aconteceu em África também quando os países europeus começaram a financiar o cinema africano: Os griots 
[nome pelo qual é conhecido uma espécie de curandeiro da África Central especialmente de língua francesa] eram quase obrigatórios nos filmes e essa paisagem do campo e da aldeia africana ainda está muito presente no cinema africano dessa altura. Mais recentemente, foi a emigração que se tornou moda... Ou seja, os financiamentos determinam as escolhas dos temas e dos modelos como os filmes são produzidos e isso leva a uma estética que só algumas vezes é rompida em África. Existem teorias e experiências que foram feitas (e outras que se tentam atualmente) que são pistas importantes (o chamado ritmo africano da montagem, as volumetrias e os espaços no cinema de Cissé, entre outras). Eu imagino que as volumetrias e as cores são outros elementos básicos em África, cuja correspondência estética tem ainda de ser melhor explorada. Depois, e mais importante que tudo, existe o mundo espiritual - profundamente habitado por personagens, símbolos etc - que constitui um enorme contributo para essa estética. Mas, eu não creio que haja uma "driven force" da estética africana. Existem experiências muito interessantes. Existe potencial. Finalmente, o conceito de estética africana tem de ser assumido no tempo. É uma realidade visual dinâmica...

MGM - Você poderia falar do papel dos "animais símbolos" no filme, como o impala em $O$ Jardim do outro homem?

SC- Sou um fotógrafo de vida selvagem nos meus tempos livres. É uma paixão enorme. Fiz até programas educativos para crianças sobre os principais animais selvagens de Moçambique. Percebi que os animais têm comportamentos complexos que o homem não consegue ter. A luta pela sobrevivência é essencial. Ora, a impala é um animal bastante comum em Moçambique. Mas pouca gente sabe que uma fêmea pode segurar o parto durante duas semanas ou mesmo abortar, se as condições de sobrevivência não forem boas. Eu achei que a heroína do filme estava numa situação dessas. Fazer nascer o seu sonho ou abortá-lo? O animal tropeça, salta, foge e essencialmente olha o espectador frente a frente, tal como Sofia, a heroína. Por isso, resolvi colocar a impala no filme. Tem mais um elemento: se você for ver a forma tradicional como os mais velhos educam as crianças em África (Cf. Usos e costumes dos bantus, de Junod), apercebe-se, facilmente, que um simbolismo oriundo do mundo animal é usado quase sempre.

MGM - Qual é o papel do cinema como instrumento pedagógico? Existe contradição entre cinema lúdico versus cinema educativo? 
SC- Existe apenas uma contradição real no cinema: entre o bom cinema e o mau cinema. Desculpa o radicalismo, mas o resto é conversa de café. Qualquer filme pode, em minha opinião, ser um instrumento pedagógico. Existe o ensino com "imagens em movimento", mas isso não é cinema. Uma hora e meia de explicação sobre um tema não faz um filme. (Como disse atrás, eu fiz 14 programas de animais selvagens em Moçambique para crianças. Era pedagogia e ensinava... Mas não era cinema, nem documentário... Disso estou claro...). A minha posição mais profunda sobre o tema está no meu texto sobre o pedagógico no cinema.

MGM - E o cinema de função social versus espaço de liberdade, criação?

SC- Mais uma vez, me parece uma falsa questão. Se é para o ser humano, então é social. Todas as chamadas "funções do cinema" (sejam sociais, históricas, transformadoras, lúdicas, etc) correspondem a um espaço de liberdade e de criação artística. Num filme pode-se exercer esse espaço com mais ou menos liberdade, mas sempre criativamente. Mas, existem mitos que é preciso derrubar também. Eu tenho mais respeito por um cineasta chinês que consegue fazer um filme condenando "ligeiramente" o seu regime do que tenho por um francês a criticar o Presidente François Holande. $\mathrm{O}$ ato de coragem do primeiro é infinitamente superior ao segundo.

MGM - Qual é a relação do cinema com o poder político, uma vez que o cinema, principalmente nos países descolonizados, recebe patrocínio do próprio Estado? O cinema não poderia contribuir, fazendo uma leitura crítica da administração deste mesmo Estado?

SC- Uiii... O cinema só não recebe patrocínio em países, em que o mercado possibilita que o custo de produção da mercadoria seja compensado pela sua compra e dê lucro até. E eu não conheço nenhum país com menos de 90/100 milhões de habitantes que o tenha conseguido fazer. Um filme custa mais caro na Europa e nos Estados Unidos do que na China. Na Europa, se for visto por 400.000 pessoas, é um super sucesso. Tem até direito a um apoio automático para o próximo filme. Na China, o mesmo filme que foi mais barato de fazer, se for visto pelas mesmas pessoas, é um flop! Por outras palavras, é mais fácil um flop na China pagar o custo do filme e dar lucro, de que um sucesso na Europa. A diferença que existe é que, nas democracias ocidentais, estão mais disponíveis a financiar um cinema que pode ser crítico. Quanto aos africanos, não existe simplesmente apoio do Estado. 
MGM - Qual a contradição entre o cinema de encomenda e o cinema de autoria? Qual seria a combinação possível?

SC- O cinema de encomenda pode ser um cinema de autoria. Aliás, em última análise, é isso que se passa na publicidade... Mas também pode acontecer no documentário. E nossa empresa produziu recentemente um exemplo (estou à vontade, pois não fui que o dirigi). E depois o que se passa quando um editor do National Geographic diz que quer um documentário sobre leões a tomar banho em piscinas africanas? Não está a fazer uma encomenda? Imagino que a pergunta se refere a outro problema relacionado e que convém colocar nos devidos termos. Certo cinema de encomenda traz consigo a arrogância do interlocutor que, por ser o portador do dinheiro, se arroga no direito de saber como fazer o filme. Esse tem sido um dos maiores cancros dum cinema que se pretende pedagógico, educativo, etc. Mas, que, na verdade, não é mais do que um palco, onde meninos e meninas estúpidos, atrás da mentira, da ajuda aos pobrezinhos, dizem às pessoas pobres como se devem comportar... E todas elas têm o desejo secreto de dizer, no seu círculo de amigos, que foram elas que "dirigiram" aqueles filmes. E, apesar do meu ódio a esses burguesinhos de pacotilha armados em artistas, acho fundamental que a indústria dos países pobres consiga dialogar com algumas organizações e seus líderes para, em vez de se tentarem substituir aos técnicos e artistas, aceitarem um espaço de diálogo construtivo, em que ambas as partes saem a ganhar. É uma luta titânica, porque esse setor financia grande parte do nosso cinema, mas por vezes não deixa de ser desesperante... E a minha experiência mostra que o pior destes setores é precisamente o do HIV. Já tive uma encomenda de filmes de ficção em que a "expert" dirigia filmes sobre o combate ao HIV SIDA, a partir do Peru, duma organização que enviou outro expert de Nova York para decidir como os atores deveriam estar vestidos. Tudo num filme feito por técnicos moçambicanos com larguíssima experiência de trabalho nesta área... E mesmo de discussão dos filmes sobre essa matéria com as comunidades. Enfim, a iniciativa presidencial americana contra a SIDA encobriu alguns dos maiores crimes educacionais que se fizeram em África. É uma história que ainda está por se contar...

MGM - Poderia falar sobre o papel entre o "realismo mágico" e o imaginário mítico no cinema africano?

SC- O chamado "realismo mágico" corresponderá a correntes já estabelecidas nas literaturas e outras artes da América Latina, por exemplo. García Marquez será, 
talvez, o expoente mais conhecido, mas não será o único. Mas, emergindo de sociedades completamente mergulhadas num mundo mágico animista, profundamente enraizado, a existência do "realismo fantástico" em países recentemente independentes é quase uma evidência! Dificilmente consigo ver um cinema africano e uma estética africana sem serem habitados por esses signos e pelas lógicas que o mundo espiritual exerce nas pessoas.

MGM - Quais são os conflitos e complementaridades entre o cinema, televisão e outras mídias?

SC- Steven Spielberg e George Lucas diziam, recentemente, que, dentro em breve, o espetáculo na sala de cinema será dos mais caros, e que o cinema, como o conhecemos, será do domínio das TVs. Ele falava, com razão, de que sair de casa para ir a uma sala, passando pelo frio, problemas de estacionamento, etc, só pode ser feito, se a oferta for boa e variada, e se as pessoas não a puderem encontrar em casa. Por isso, se fala do espetáculo multimídia.

Recebida em 16 de maio de 2015. 